\title{
From cost reduction to revenue growth: Shifting priorities for digital asset management
}

\author{
Eric M. Hoffert \\ has more than 20 years of experience leading new business, product, and technology development in enterprise software, \\ collaboration, and rich media. He is CEO of Versatility Software, Inc. a digital media and collaborative content consultancy with clients \\ including Campbell's Soup, Unilever, The News Market, Stanford and Carnegie Mellon Universities. Previously, he was Co-Founder, CTO, \\ and Chairman of the Board for Magnifi, a digital asset management service provider, before which he managed Apple Computer's \\ Multimedia Communications Group. Prior to joining Apple, Eric was a research scientist at AT\&T's Bell Laboratories. He holds 11 \\ patents, has published more than a dozen papers, and has lectured in the USA, Europe, and Asia. Eric holds a BS in CS from NYU, a \\ BSME from Cooper Union, and an MS in CS from the Courant Institute of Mathematical Sciences at New York University.
}

Keywords: digital rights management, digital asset management, media e-commerce, content monetization, media on-demand

\begin{abstract}
A fundamental shift and a new priority is starting to emerge for digital asset management (DAM). In the area of business benefits for DAM, a strong emphasis has been placed on cost reductions, such as the reduced amount of time finding content; lowered costs for express mail, shipping, and couriers; a replacement of manual systems with automated workflows; eliminating the need for CD-ROM or paper distribution of content and market messaging, etc. These cost savings can now be considered traditional, or canonical cost reduction methodologies for DAM. Indeed they are extremely important reasons for many organizations to build, deploy, maintain, and enhance a DAM infrastructure. As a result, most $\mathrm{ROI}$ models for DAM are based on combinations of cost reductions and productivity gains. However, after all of the cost reduction focus in recent years, attention is turning to new methods of leveraging DAM to generate new streams of revenue and profit. There is a particularly strong interest in content monetization where revenues derived from digital assets, or systems that deliver and track them, can grow rapidly with only a modest cost basis. Beyond conceptual interest, there are now a number of commercial systems rapidly validating this new direction including revenue generating content models from Apple Computer (iTunes Music Store), Adobe (Digital Media Store), Getty Images, CNBC Business Video, National Geographic Images, and many others.
\end{abstract}

Eric M. Hoffert Versatility Software Inc 349 Montrose Avenur South Orange, NJ 07079, USA Tel: +19737629323 Fax: +19737628209 Email: eric@versatility-inc.com

\section{INTRODUCTION}

During the boom, companies took to the internet with vigor, speed, and large

investments. A primary focus was to launch ecommerce sites to sell physical goods with an electronic presence or to promote and sell electronic content. A number of fortunes were made and many were lost.

The last three years, during the bust, have been a time period with intense focus on cost reduction. Coming out of the boom period, companies focused, often maniacally, on streamlining operations with a goal towards profitability. The profit goal was demanded not only by Wall Street for public companies but in the private sector as well, where venture capital became scarce and the viability to continually service customers was often based on an independent ability to achieve cash flow positive status or better in operations. Many jobs were lost in the USA due to downsizing and the broader trend of offshore outsourcing began to take hold in a major way.

Many unprofitable operations were shut down or massively restructured. In the same timeframe underlying shifts for the cost of technology operations were quite dramatic - the cost bases for telecommunications, hosting/bandwidth 
costs, and storage tumbled, coming down in some cases by two or even three orders of magnitude. Similarly, the trend away from expensive enterprise licensed platforms for multi-tier application infrastructure to low-cost, or in many cases, no-cost platforms for open source have completely transformed the economics of building software, making it far easier than ever to construct a corporate IT initiative or a new software product at minimal cost. The emergence of software as a service has lowered costs even further, allowing a utility like approach where software can be purchased as-needed, at-your-service, for low monthly fees.

Along with these tectonic shifts in the cost basis for technology operation, higher-level changes in the economy beyond offshore outsourcing and restructured staffing levels produced thousands of companies in a "lean and mean" operational mode. After a period of significant overspending in the boom, many companies achieved a new period of minimal expenditures concomitant with a more predictable and sustainable profitability. Major changes in the underlying cost bases had taken place to the point that major costs had been squeezed out of most budgets. For many companies, the number and scope of cost reductions has come to the point where the ability to further reduce costs was quite constrained.

In the broader context, after a few years of stagnation in the stock market, with job losses and sluggish job growth, it appears that there is a new tack on economic growth. With many companies operating with a dramatically lower cost basis than before, there is a shift towards revenue generation and new growth. After all, you cannot save more than you spend; so cost savings by definition are limited by expenditures. However, new revenues are ultimately limited only by the imagination used to apply a digital asset management (DAM) system to the opportunity. Hence, companies are finally looking towards new avenues to build revenue and profits now that they have an underlying smart and low-cost infrastructure to enable it. The next great challenge is to leverage the remarkably low-cost basis into financial upside and new opportunities that are widely scalable.

These broader trends mirror what has been happening with DAM systems. A great deal of emphasis in recent years has been placed on cost reductions such as the reduced amount of time finding content; lowered costs for express mail, shipping, and courier; a replacement of manual systems with automated workflows; eliminating the need for CD-ROM or paper distribution of content and market messaging, etc. These are now what can be considered traditional, or canonical cost reduction methodologies for digital asset management. Most ROI models for DAM are based on combinations of cost reductions and productivity gains. After all of the cost reduction focus, attention is turning to new methods of leveraging digital asset management to generate new streams of revenue and profit. There is a particularly strong interest in content monetization where revenues derived from digital content can grow rapidly with only a modest cost basis.

Just in the last 12 months, there has been remarkable progress in this new direction. Progress has been made across three broad categories - business to consumer, business to business, and in advertising and marketing services. These advances are detailed below.

\section{Business to consumer}

Most notably, the world of digital media ondemand for consumers has exploded overnight. This category would include digital music and movies. The largest revenues generated to date for any DAM-based system with digital rights management targeted at pure consumer delivery have come from Apple Computer and the iTunes Music Store. In the first year of operation, the iTunes Music Store has sold more than 50 million songs ${ }^{1}$ with 125 terabytes of content downloaded. Assuming a list price of $\$ 0.99$ per song this figure represents $\$ 50 \mathrm{~m}$ in revenue with operations now at a $\$ 2.5 \mathrm{~m}$ a week or a $\$ 100 \mathrm{~m}$ plus annual run rate. By providing a strong digital rights management (DRM) solution (which is called FairPlay) ${ }^{2}$ so that content cannot be copied to more than three devices, along with a networked based metadata service which can be updated dynamically (the CD Data Base (CDDB) encoding platform from Gracenote ${ }^{3}$ now used by more than 30 million people in 130 countries), requirements for security and ease of use were sufficient to achieve critical buy-in 
from the content providers to enable their media for distribution and purchase.

Apple's iTunes platform contains fundamental components of a traditional DAM system searching and browsing of multimedia content with a domain-specific taxonomy and metadata schema, download access and shopping carts for purchase, metrics on popularity and downloading activity, along with deeply integrated DRM usage inside and outside of the system (as business rules governing the content are connected with, and travel with the media itself). A raft of competitive services from WalMart, RealNetworks, Dell, Buy.com, and many others are entering the market now, competing for what could be a major alternative to physical products for music distribution. With an existing market for music CDs in the USA on the order of $\$ 11 \mathrm{bn}$ and approximately $\$ 40 \mathrm{bn}$ worldwide ${ }^{4}$ and a PC music on-demand market that is arguably more than 20 times larger than the Macintosh market, it is not inconceivable that the currently modest but rapidly growing digital music market could very quickly become a multi-billion dollar market.

This market growth can all occur using the same basic digital asset management infrastructure for media management, distribution, and commerce. Ultimately the marginal cost for servicing more customers is small while the potential for a much larger market is very high and hence profits could grow quickly. The Apple iTunes Music Store has also shown us the potential of "frictionless commerce" for content monetization — if you can efficiently connect buyers (consumers) with sellers (record companies) in the same way that eBay connected buyers and sellers for physical goods you may be able to build a remarkably efficient engine for buying and selling digital media content.

Video has also entered the picture with services such as MovieLink and CinemaNow. These systems have started to gain traction but not yet in the explosive manner that has been seen with Apple's iTunes music store. This may be due to the fairly restrictive time periods set for access to digital media (typically 24 hours of playback only after an initial download). Once these issues are ironed out it is feasible that movies on-demand could also rapidly grow to a major market.

\section{Business to business}

For businesses, an ability to generate revenue from asset-managed content is growing. This is true for service providers and intermediaries delivering business media content such as Getty Images and Corbis, where Getty's recent financial results for 2003 included approximately $\$ 525 \mathrm{~m}$ in revenues and $\$ 65 \mathrm{~m}$ in profit $^{5}$ with rapid growth. Highly relevant to mainstream DAM platform purchasers - companies whose sole business is not to serve as an intermediary are also seeing good results in this new arena. Notable examples of this trend include National Geographic with their National Geographic Images Commerce site for rights managed photography; ${ }^{6}$ the National Geographic Images site contains more than 10,000 images for sale to professionals in fields such as advertising and publishing, Another notable example is CNBC Dow Jones Business Video with its video commerce services platform. CNBC has developed its business video service offerings for daily syndication, subscriptions, and video reprints. ${ }^{7}$ More than 20,000 business news media assets from within a year of broadcasting material are available on-demand, including 6,000 video clips in streaming format along with transcripts for business customers. Time from air to web for the streaming video content is no more than 15 minutes. CNBC has three different use cases which drive the monetization of content: video use by financial professionals on intranets for investment research and analysis; syndication of video content onto internet sites to drive traffic and advertising revenues; and company specific video "reprints" on internet or intranet sites to highlight video news announcements to employees, media, partners, and investors. Even recent work at Ford Motor Company ${ }^{8}$ is of note, where internal chargebacks for services in a large organization provide a form of internal revenue streams that reduce base costs and provide new upside for a corporate DAM solution.

\section{Advertising and marketing services}

Advertising and marketing service agencies are taking a lead in the area of revenue growth as well. After many years of focusing on DAM solutions to support cost reductions for content access and minimizing cycle times for production, a new shift is emerging to generate 
new streams of revenue from these same systems - adding to overall ROI and providing potential for a truly scalable and additive revenue stream. A notable development in the advertising and marketing services space is a system created by BBDO, one of the leading advertising agencies. BBDO created a DAM system that allows for management and distribution of media assets for creative reviews, approvals, and distribution across multiple regional and worldwide offices. The system has been so successful for both internal and client use that it has spawned a new business called Workflow.Biz. ${ }^{9}$ Workflow.biz, built upon a foundation of Artesia, Oracle, and Telestream components, allows for generation of new revenues from solution sales to clients outside of the advertising and marketing arena, as a more general-purpose asset management and workflow product and solution. In addition, the BBDO platform can generate service fee revenues for end-user requested copies of video content - revenues that were previously taken by outside service providers in the area of video duplication. Finally, there is revenue that can be generated via service fees for the use of client extranets - enabling access to content ondemand for work in progress, archival work, and competitive advertising. This model may be replicable across the advertising segment - at least in part - and could support advertising agencies with new streams of revenue to complement their standard service offerings. For the marketing services area, an interesting development is from Sonera, Finland's largest telecommunications firm. After an extensive analysis of manual labor and inefficiencies in its standard marketing processes, Sonera created a blueprint for optimized work processes with varying degrees of automation. Subsequently, they created a digital asset management and workflow platform ${ }^{10}$ for marketing services to embed the enhanced processes into software, providing cost reductions and reduced time to market. The project has been successful, and is now in a commercialization phase where it may be licensed for use by third parties external to the Sonera user community, presenting new opportunities to generate revenue for Sonera.

In summary, a trend is now emerging where new sources of revenue tend to accompany traditional cost reductions and productivity enhancements as key components that comprise ROI. The monetization element has potential to be the most scalable and highest leverage element of ROI. Achieving DAM monetization and new revenue across a broader set of companies does come with challenges. Technical issues still present obstacles - there are no widespread standards yet for DRM or for media commerce in general. And asset metadata still have no universal mechanism to travel inside an asset with a full description of ownership and business rules on access and purchase. New concepts are under discussion to address some of these issues — "SmartAssets" 11 is described as an ability for metadata to be embedded within an asset and to travel across multiple production and distribution processes, and "SmartServices", represents an ability to allow read, write, and query media access to a DAM system to occur through a standardized web services interface layer; both ideas may help to provide a more open and standards-based environment for media commerce. Similarly, emerging standards for rights management may boost the use of common mechanisms for media commerce management. For now, however, the technology landscape to generate revenue from content is fragmented; although viable solutions can be brought to market; more work is needed for enhancements to see this arena transition to mainstream and broad accessibility across industries and platforms.

What does this set of trends mean for a business of any kind considering a DAM solution or looking to expand their existing DAM platform? Quite simply it shows that new streams of revenue from a DAM platform are not only feasible but are happening today. New revenue generation opportunities for DAM are emerging now with increasingly positive results - across consumer, business, and advertising segments. This is true for companies serving as intermediaries for content providers as well as companies that go direct to end-users with their services and content. Cost reduction and cutting cycle times is still key for any DAM solution and offers many benefits. But, planning for new revenue generation should and can be more prominent in the development of DAM solutions — which should result in higher ROI and stronger business cases overall for businesses of many kinds. 


\section{References}

1 Fried, I. (2004) “Apple iTunes Sales Hit 50 Million”, CNET News.com, March 15. http:// news.com/Apples + iTunes + sales + hit $+50+$ million/2100-1027_3-5173115.html.

2 Salkever, A. (2004) "Digital Music: Apple Shouldn't Sing Solo", Business Week Online, March 24. http://www.businessweek.com/ technology/content/mar2004/ tc20040324_2586_tc056.htm.

3 Copeland, $\bar{M}$. (2004) "The Magic Behind the Music”, Business 2.0, March. http://www.business2. com/b2/web/articles/0,17863,581069,00.html.

4 Recording Industry Association of America (2004) 2003 Year End Marketing Reports on US Shipments, PricewaterhouseCoopers LLP, March. http:// www.riaa.com/news/newsletter/pdf/ 2003yearEnd.pdf.

5 Reuters (2004) Abridged Financial Summary for Getty Images, Inc., http://finance.yahoo.com/q/ $\mathrm{pr} ? \mathrm{~s}=\mathrm{GYI}$.

6 Olsen, S. (2002) "National Geographic is Wild about Digital", CNET News.com, November 25. http://news.com.com/ National + Geographics + wild + about + digital/ 2100-1023_3-975289.html
7 Gomah, G. (2004) "Ford Motor Company: Digital Asset Management", presentation at the Henry Stewart Digital Asset Management Conference, Brooklyn, NY, March 29-30.

8 Morgenstern, K. (2003) "CNBC Dow Jones Business Video: Building a Long Term Digital Media Business", presentation at the New Media Forum Conference, La Quinta, California, September 22-24.

9 Pannuto, D. (2004) "DAM as a Profit Center and not a Cost Center: Creating New Opportunities and New Revenues", presentation at the Henry Stewart Digital Asset Management Conference, Brooklyn, NY, March 29-30.

10 GISTICS (2004) "Business Case for a Marketing Services Platform in the Global Enterprise:

Strategies, Best Practices, and Business Metrics for Managing Global Multichannel Marketing Programs for Profit Maximization”, GISTICS White Paper, Proceedings of the Henry Stewart Digital Asset Management Conference, Brooklyn, NY, March 29-30.

11 G-SAM (2004) "New York G-SAM Chapter Meeting”. NYC G-SAM Chapter Meeting Minutes, Brooklyn, NY, March 30. 